\title{
Targeting Asymptomatic Term and Late Preterm Newborns at Risk for Early Sepsis: C Reactive Protein 20mg/L Threshold
}

\author{
Margarida Ejarque-Albuquerque ${ }^{*}, 1$, Graça Oliveira ${ }^{1}$, Tiago Santos ${ }^{1}$, Duarte Rebelo ${ }^{1}$, Carlos Moniz ${ }^{1}$ \\ and Teresa Rodrigues ${ }^{2}$ \\ ${ }^{I}$ Neonatal Service, Paediatric Department, Santa Maria University Hospital, Lisbon, Portugal \\ ${ }^{2}$ Biomath Laboratory, Faculty of Medicine, University of Lisbon, Portugal
}

\begin{abstract}
Identification of sepsis is a major issue due to limitations in diagnosis and severity of outcome. Different combinations of tests are used to screen babies at risk for infection, none specific enough to avoid treatment of noninfected newborns. 193 newborns with $\geq 35$ weeks of gestational age admitted in the maternity were screened for infection using a protocol scoring system involving haematological values and CRP $\geq 10 \mathrm{mg} / \mathrm{l}$. Blood-cultures were taken after treatment decision, before antibiotics were started. No microbiological exam was included in the screening. Treatment decisions were taken by the staff irrespectively of the ongoing observational study.

Newborns were classified by the authors in 4 groups: infected (culture verified), strongly suspected infection (SSI), no sepsis but treated (NST), no sepsis-no treatment (NSNT). Treatment decision was revaluated by the authors according to different cut-off levels of CRP.

40 newborns (20.7\%) received antibiotics. 2 had positive blood-cultures. 13 were classified as SSI (all treated) and 178 as not infected (25 treated). All infected babies were identified but the error of the positive predictive value reached $62.5 \%$.

Revaluation of treatment decisions with CRP cut-off levels of 15, 20 and $25 \mathrm{mg} / 1$ showed respectively $60.5 \%, 51.6$ and $48 \%$ of error of the positive predictive value, the first two cut-offs missing no infected newborns but the last one missing two.

A new scoring system including CRP at $20 \mathrm{mg} / 1$ has been in use since then without readmissions for infection and an estimated reduction of $24 \%$ antibiotic treatment.
\end{abstract}

Keywords: Antibiotics, CRP, newborn, screening, sepsis.

\section{INTRODUCTION}

Identification of early neonatal sepsis is a major issue due to limitations in diagnostic procedures and severity of the outcome. The gold-standard positive blood-culture has very low sensitivity [1]. Minimising antibiotic exposure without risk is not an easy task [2-5]. Different screening tests and combination of tests including acute-phase reactants, haematological scoring systems (HSS) and, recently, cytokines, are used, the optimal selection of which is yet to be determined. Cost can also be limiting. Good negative predictive values can be obtained at 12 - 24h of life $(99 \%)$ [6] with C-reactive protein (CRP) and HSS but specificity is generally not good enough to avoid treating non infected newborns [7-9]. Newborns generally have a physiological induction of inflammation values in the first few days after birth, and a moderate elevation of acute-phase reactants does not necessarily indicates sepsis. Cut-off levels of CRP vary among authors from 5 to $50 \mathrm{mg} / 1$ [10-14]. CRP increases in 4-6h after an inflammatory trigger and peaks around $36-50 \mathrm{~h}$.

*Address correspondence to this author at the Hôpital Louis Pasteur, Service de Pédiatrie, 4 Rue Claude Bernard 28630 LE COUDRAY France; Tel: 0033237303030; Fax: 0033237303125;

E-mails: guida.ejarque@gmail.com, mejarque@ch-chartres.fr
Error of the negative predictive value of CRP screening at birth (cord blood) is $12 \%$ and sensitivity $20 \%$, making it not useful by that time [15].

The authors evaluated the screening protocol in use at the maternity ward of Santa Maria University Hospital in Lisbon, proposed a new cut-off level for CRP and present the follow-up after changes have been implemented.

\section{STUDY DESIGN}

The authors evaluated the cut-off level of CRP as a septic marker in use in the maternity ward. All newborns with $\geq 35$ weeks of gestational age (GA) at risk for infection admitted during 2006 were enrolled prospectively. Treatment decisions were taken by the staff irrespectively of the ongoing observational study. By then, the protocol for septic screening involved a scoring system (positive $\geq 2$ ) including CRP and leukocyte count. (Table 1). Reference range in our laboratory for a negative CRP is $<5 \mathrm{mg} / 1$.

A negative screening by $24 \mathrm{~h}$ of age was not repeated. Results from CRP and HSS were evaluated until a decision was taken. Blood-cultures were done only after a positive treatment decision, before antibiotics were started. No peripheral or gastric fluid microbiological exam was included as part of the screening tests. 
Table 1. Septic Screening Scoring System (Treat if $\geq 2$ )

\begin{tabular}{|c|c|c|}
\hline & 1 & 2 \\
\hline $\operatorname{CRP}(\mathrm{mg} / \mathrm{L})$ & $\geq 10$ & $\geq 20$ \\
\hline Leukocyte count $/ \mathbf{m m}^{3}$ & $<7500$ or $>30000$ & $<5000$ or $>40000$ \\
\hline Neutrophil count $/ \mathbf{m m}^{3}$ & $<1500$ & $<1000$ \\
\hline Immature N/Total Neutrophil & $\geq 0,2$ & $\geq 0,3$ \\
\hline
\end{tabular}

Newborns were afterwards classified by the authors in four groups: infected (culture verified), strongly suspected infection (SSI) no sepsis but treated (NST), no sepsis-no treatment (NSNT).

To classify a newborn as SSI it was necessary to meet at least one of the following criteria: CRP $>50 \mathrm{mg} / 1$, positive screening score in the baby and multiple risk factors, positive screening score and clinical alteration, readmission for sepsis within one week after discharge (telephone control).

The authors revaluated treatment decision for each newborn according to different cut-off levels of CRP within each group.

\section{RESULTS}

From the 2771 births at Santa Maria University Hospital during 2006, $2478 \mathrm{NB}$ were admitted in the maternity ward (well babies). 193 presented risk for infection. 50.3\% were girls. Mean GA was 38,7 weeks (SD 1.4), 37\% born by caesarean section. Risk factors were: mother colonization with group B Streptococcus without correct prophylaxis $33 \%$, prolonged rupture of membranes $(\geq 18 \mathrm{~h})-46 \%$, maternal fever during labour $\left(\geq 38^{\circ} \mathrm{C}\right)-17 \%$, amnionitis $3 \%$, documented recent urinary tract infection (last week before birth) without treatment - 8\%; multiple risk factors $11 \%$. Spontaneous prematurity by itself was not considered a risk factor for screening. 40 newborns $(20.7 \%$ from those considered at risk) received antibiotics. The number of analysis before a decision was taken to treat or not to treat varied from one to four. Six babies were lost for the followup.

From the 187 babies with complete follow-up, two had positive blood-cultures. This represented $5 \%$ of the blood cultures. Bacteria identified were Lysteria monocytogenes in one case and Staphylococcus aureus in the other. 13 newborns (7\%) were classified as strongly suspected of infection (all of them treated), 25 babies (13.4\%) were classified by the authors as not infected but treated and 147 $(78.6 \%)$ were classified as not infected and not treated. All infected newborns were identified (negative predictive value $100 \%$ ) but the error of the positive predictive value reached $62.5 \%$.

$\mathrm{CRP}$ in the moment of decision varied from 1 to $16 \mathrm{mg} / \mathrm{l}$ for not treated newborns and 10 to $151 \mathrm{mg} / \mathrm{l}$ for treated ones. CRP for infected and SSI (all treated) varied between 22 and $151 \mathrm{mg} / \mathrm{l}$; for NST babies from 10 to $48 \mathrm{mg} / 1$. 1 to 4 blood analyses were done before reaching a decision, within the first $72 \mathrm{~h}$ of age. No infant was readmitted for sepsis.
Revaluating the CRP level in the scoring system showed that the use of $15 \mathrm{mg} / 1$ as the cut-off level would have screened for treatment 23 NB not infected without missing any SSI, reducing the error of the positive predictive value to $60.5 \%$. Cut-off level at $20 \mathrm{mg} / 1$ would have screened for treatment 16 not infected NB without missing any SSI with a reduction of the error of the positive predictive value to $51.6 \%$. A cut-off level at $25 \mathrm{mg} / 1$ would have screened for treatment 12 newborns not infected (error of the positive predictive value $48 \%$ ) but would have missed 2 strongly suspected (error of the negative predictive value of $1.3 \%$ ). (Table 2)

Table 2. Error of the Negative and Positive Predictive Values for Different CRP Cut-Off Levels

\begin{tabular}{|c|c|c|c|}
\hline \multirow{2}{*}{ Cut-Off } & \multirow{2}{*}{ Infected/Strongly Suspected Infection } \\
\cline { 3 - 4 } & & No & Yes \\
\hline \hline \multirow{2}{*}{ CRP mg/l } & $<15$ & 149 & 0 \\
\cline { 3 - 4 } & $\geq 15$ & 23 & 15 \\
\hline
\end{tabular}

Error of the negative predictive value: $0 / 149=0 \%$

Error of the positive predictive value: $23 / 38=60.5 \%$

\begin{tabular}{|c|c|c|c|}
\hline \multirow{2}{*}{ Cut-Off } & \multirow{2}{*}{} & \multicolumn{2}{|c|}{ Infected/Strongly Suspected Infection } \\
\cline { 3 - 4 } & & No & Yes \\
\hline \hline \multirow{2}{*}{ CRP mg/l } & $<20$ & 156 & 0 \\
\cline { 3 - 4 } & $\geq 20$ & 16 & 15 \\
\hline
\end{tabular}

Error of the negative predictive value: $0 / 156=0 \%$

Error of the positive predictive value: $16 / 31=51.6 \%$

\begin{tabular}{|c|c|c|c|}
\hline \multirow{2}{*}{ Cut-off } & \multirow{2}{*}{ Infected/Strongly Suspected Infection } \\
\cline { 3 - 4 } & & No & Yes \\
\hline \hline \multirow{2}{*}{ CRP mg/l } & $<25$ & 160 & 2 \\
\cline { 3 - 4 } & $\geq 25$ & 12 & 13 \\
\hline
\end{tabular}

Error of the negative predictive value: $2 / 162=1.2 \%$.

Error of the positive predictive value: $12 / 25=48 \%$

\section{DISCUSSION}

Staphylococcus aureus is not a frequent agent of earlyonset neonatal sepsis and several authors in different studies consider it as a contaminant. Nevertheless we decided to classify the baby with the blood culture positive for that agent as infected. He also had a positive score and the same agent was identified in his mother's urine in the context of a urinary tract infection.

From the 187 newborns included in the study, 172 were posteriorly considered as probably not infected. Using CRP cut-off levels of $15 \mathrm{mg} / 1$ and $20 \mathrm{mg} / 1,23$ and 16 newborns would have been unnecessarily treated, respectively, without missing any strongly suspected of infection. The cut-off level of $25 \mathrm{mg} / 1$ was dismissed as it would have missed two babies with strongly suspected infection.

A new scoring system was therefore proposed based in CRP at 20mg/l, HSS (values by hours of age) [16] and clinical symptoms that has been in use since then without 
readmissions for infection and an estimated reduction of $24 \%$ antibiotic treatment of newborns at risk for early onset sepsis not infected.

Recommendations from the Center for Diseases Control regarding B Streptococcus infection prophylaxis during labour have changed since 2010 and fewer babies would have been screened according to the new guidelines $[6,17]$. Therefore some of the screened newborns were probably not really at risk, but they were probably in the group "not infected and not treated", without major alteration in the estimated reduction of antibiotic treatment.

A faster marker like procalcitonin may be useful, avoiding repeated screening. Time adjusted reference range must be used for the first few days of life but a low level at birth (cord blood) seems to have a very high negative predictive value $[18,19]$. Other promising markers currently being evaluated like neutrophil CD64 and interleukine 6 $[20,21]$ lack evidence based results to substitute old markers and represent an important additional cost.

This paper specifically addresses the screening of asymptomatic neonates at risk for early sepsis. This represents about $10 \%$ of term and late preterm newborns. If we admit that only about 0.5 to $1 \%$ of asymptomatic newborns will effectively be infected and also that these babies are at increased risk for secondary effects of antibiotic treatment but also at risk for a rapid and fatal evolution if infected, it is important to develop strategies to target treatment as best as we can.

This study, as most addressing the same subject, is limited by the fact that withholding treatment is difficult to accept or clearly not possible according to present protocols and starting treatment obviously interferes with evolution, both clinical and laboratorial.

A negative blood culture has a small negative predictive value; Therefore it is difficult or impossible to really distinguish infected from non infected newborns without undue risk for the babies.

The threshold of $20 \mathrm{mg} / \mathrm{L}$ for $\mathrm{C}$ reactive-protein within 24 - $72 \mathrm{~h}$ of age seems the best negative predictor, not compromising newborn safety.

\section{CONFLICT OF INTEREST}

The authors confirm that this article content has no conflicts of interest.

\section{ACKNOWLEDGEMENT}

Declared none.

\section{REFERENCES}

[1] Connell TG, Rele M, Cowley D, Buttery JP, Curtis N. How reliable is a negative blood culture result? Volume of blood submitted for culture in routine practice in a children's hospital. Pediatrics 2007; 119(5): 891-6

[2] Philip A, Mills P. Use of C-reactive protein in minimizing antibiotic exposure: experience with infants initially admitted to a well-baby nursery. Pediatrics 2000; 106: e4.

[3] Escobar GJ. The neonatal "sepsis work-up" : personal reflections on the development of an evidence-based approach toward newborn infections in a managed care organization. Pediatrics 1999; 103: 360-73.

[4] ANAES. Diagnostic et traitement curatif de l'infection bactérienne précoce du nouveau-né. Synthèse des recommandantions. Sept 2002. Available from: http://www.has-sante.fr/portail/upload/docs/ application/pdf/synthese-_inn_-_mel2006.pdf

[5] Freitas C, Albuquerque $\bar{M}$, Stone R, et al. Parâmetros laboratoriais no recém-nascido com risco infeccioso. Criança 1987; 3: 83-8

[6] Jolivet RR. Centers for Disease Control and Prevention (CDC). Early-onset neonatal group B streptococcal infection. 2002 guidelines for prevention. J Midwifery Womans Health 2002; 47: 435-46.

[7] Kawamura M, Nishida $H$. The usefulness of serial C-reactive protein measurement in managing neonatal infection. Acta Paediatr 1995; 84:10-3.

[8] Benitz WE, Han MY, Maden A, Ramachandra P. Serial serum Creactive protein levels in the diagnosis of neonatal infections. Pediatrics 1998; 102: e41.

[9] Benitz WE. Adjunct laboratory tests in the diagnosis of early-onset neonatal sepsis. Clin Perinatol 2010; 37: 421-38.

[10] Pereira A, Marques M, Casanova C, Neto MT. Risco Infeccioso e rastreio séptico. In Secção de Neonatologia da Sociedade Portuguesa de Pediatria. Consensos Nacionais em Neonatologia. Coimbra 2004; 185-90.

[11] Aujard Y. Infections néonatales materno-foetales. In Bourrillon A, Chéron G. Urgences Pédiatriques. Masson. Paris 2005; pp. 187-91

[12] Weitkamp JH, Aschner JL. Diagnostic use of C-reactive protein (CRP) in assessment of neonatal sepsis. NeoReviews 2005; 6: e508-e515.

[13] Celik IH, Demirel FG, Uras N, et al. What are the cut-off levels for IL-6 and CRP in neonatal sepsis. J Clin Lab Ann 2010; 24: 407-12

[14] McWilliam S, Réadan A. How to use $C$ reactive protein. Arch Dis Child Educ Pract Ed 2010; 95: 55-8.

[15] Ejarque-Albuquerque M, Oliveira G, Cardoso B, Rodrigues T. Avaliaçao da utilidade da determinaçao da PCR e leucocitos no sangue do cordao de recém-nacsidos de termo de pretermo borderline com risco infeccioso admitidos na maternidade do Hospital de Santa Maria. RFML 2009; 14: 143-5.

[16] Manroe BL, Weinberg AG, Rosenfeld CR, Browne R. The neonatal blood count in health and disease I: Reference values for neutrophilic cells. J Pediatr 1979; 95: 89-98.

[17] Center for Diseases Control and Prevetion. 2010 guidelines for the prevention of perinatal group $\mathrm{B}$ streptococcal disease. Recommendations and reports. November 19,2010/59(RR10); 132. Available from: www.cdc.gov/groupbstrep/guidelines/guidelin es.html

[18] Meisner M. Procalcitonin - Biochemistry and Clinical Diagnosis. Bremen. Germany: Uni-Med Verlag AC 2010

[19] Kordek A, Giedrys-Kalemba S, Pawlus B, Podraza W, Czajka R. Umbilical cord blood serum procalcitonin concentration in the diagnosis of early neonatal infection. J Perinatol 2003; 23: 148-53.

[20] Kocabas E, Sarikcioglu A, Aksary N, Seydoaglu G, Seyhun Y, Yaman A. Role of procalcitonin, C-reactive protein, interleukin-6, interleukin-8 and tumor necrosis factor alpha in the diagnosis of neonatal sepsis. Turk J Pediatr 2007; 49: 7-20.

[21] Cernada M, Badia N, Modesto V, et al. Cord blood interleukine 6 as a predictor of early onset neonatal sepsis. Acta Paediatr. 2011. 10.111/j.1651-2227.2011.02577.x. [Epub ahead of print]. 